doc. dr Slobodan Šegrt ${ }^{46}$

Ilija Kolarski, M.A. ${ }^{47}$

pregledni rad:

UDK: $005.51 / .52$

339.137 .2

\title{
USLOVI EGZISTENCIJE PREDUZEĆA
}

\begin{abstract}
REZIME
Konkurencija kao opšti uslov egzistiranja preduzeća evoluirana na savremeni sistem poslovanja uzrokovana je diversifikacijom relevantnih faktora. Proces konkurencije se sastoji od tri međusobno povezana i uslovljena elementa. U prvom, analiza konkurentskih snaga pokazuje zašto su neke grane inherentno rentabilnije, ili atraktivnije od ostalih i zbog čega u tim granama raste vrednost preduzeća.

$\mathrm{U}$ drugom, karakteristike strateške grupe i i pozicija unutar nje mogu značajno da utiču na izmenu relativnog položaja preduzeća u grani i time naravno i njegove vrednosti. U trećem i poslednjem koraku, analiza lanca vrednosti služi za identifikaciju izvora konkurentske prednosti. Kreiranje vrednosti preduzeća apstrahuje ove činioce primenom različitih metoda i postupaka u određivanju tržišne pozicije. Ključne reči: konkurencija, preduzeće, vrednost, tržišna pozicija.
\end{abstract}

\section{UVOD}

Vrednost preduzeća implicirana na stvaranje u okviru određene grane, može da se kreira na dva načina. Prvi način je kada prinosi od investicija ili projekata brže rastu nego rizik, odnosno, drugi način je kada rizik brže opada nego prinosi. Pri tome, rizik se javlja u formi zahtevane stope prinosa koju nameće finansijsko tržište.

Menadžment malog broja preduzeća je spreman na investiranje u projekte tipa "mali rizik- mali prinosi". Postoji uverenje da bi takvi projekti uništili akcionarsku vrednost. Posmatrano na kraći rok, finansijsko tržište ne može sniziti zahtevanu stopu prinosa radi odgovarajućeg vrednovanja novih, manje rizičnih ulaganja. Snižavanje ove stope može se dogoditi jedino u dužem roku, kao posledica uočenih tendencija ostvarenja niskih, ali stabilnih prinosa preduzeća. Postojeći sistem za nagrađivanje menadžmenta više ohrabruje opciju povećanja prinosa, nego smanjivanja rizika, nezavisno od toga da li povećanje prinosa istovremeno znači i kreiranje vrednosti. Proizilazi da je relativno brži rast prinosa nego rizika prihvatljivija opcija za kreiranje vrednosti.

U okviru izbora uslova atraktivnosti za stvaranje vrednosti preduzeća mogu se primeniti različite analitičke funkcije, od kojih je najatraktivnija i optimalno orijentisana SWOT analiza koja označava interne snage (Strengths) i slabosti (Weaknisses) i eksterne prilike (Opportunities) i pretnje (Threats). Iz skraćenica proizilazi da su predmet izučavanja interne snage i slabosti, s jedne i eksterne prilike i pretnje, s druge strane. SWOT analiza je razvijena kao sredstvo sistemske i procesne analize i radi takvog pristupa, ona olakšava uočavanje međuzavisnosti unutrašnjih snaga i slabosti sa spoljnim prilikama i pretnjama. Te međuzavisnosti prikazuju se u opštoj ili preduzeću specifičnoj formi SWOT-matrice.

\section{ATRAKTIVNOST GRANE}

Analiza snaga i slabosti preduzeća bavi se odnosom potencijala preduzeća i potencijala njegovih konkurenata. Ekonomski potencijali, kvantitativno merljive veličine kvalifikuju se kao snage ili slabosti samo na osnovu odnosa ili razlika prema istim takvim veličinama konkurenta. Metode analize i način identifikovanja snaga ili slabosti zavisi od značaja ekonomskog sadržaja parametra. Kod pojedinačnih parametara češća je mogućnost poređenja svojstava koja se mogu kvantifikovati i ređe je potrebna upotreba subjektivnih ocena.

Primeri analize snaga i slabosti u pojedinačnim obeležjima mogu se pronaći za svaki od navedenih potencijala. Pragmatično ćemo pokazati mogućnosti ocenjivanja starosti proizvodnog programa i kvaliteta proizvoda, na vrednost preduzeća.

\footnotetext{
${ }^{46}$ Visoka škola za menadzment i ekonomiju, Kragujevac

${ }^{47}$ Računovodstveni centar, MO
} 
Starost proizvodnog programa kao potencijal i pretpostavka snage ili slabosti preduzeća može se iskazati stopom inovacija, koja se formira na sledeći način:

Stopa inovacija jednaka je rezultatu sledeće jednakosti:

prihod od prodaje svih novouvedenih proizvoda $\times 100$

prihod od prodaje svih proizvoda

Uticaj dužine $n$-godina za koji se računa ova stopa i eventualnog usporavanja prodaje ovaj pokazatelj svedoči ne samo o kratkoročnom uticaju na rentabilnost i troškove već i posebno o nemiru koji uvođenje novih proizvoda unosi u preduzeće.

Kvalitet proizvoda se izražava indeksom kvaliteta. Utvrđivanje indeksa kvaliteta ne zasniva samo na fizičkim svojstvima proizvoda već još više na subjektivnim zapažanjima korisnika ili kupaca. Indeks kvaliteta formira se na sledeći način:

Indeks kvaliteta $=\%$ promet proizvoda iznad prosečnog kvaliteta $-\%$ promet proizvoda ispod prosečnog kvaliteta

Proizvodi se po kvalitativnim osobinama (iznadprosečni, prosečni $\mathrm{i}$ ispodprosečni kvalitet) prepoznaju metodom upitnika o mišljenju kupaca i to:

Tabela 1. Primer formulara upitnika

\begin{tabular}{|c|c|c|c|c|}
\hline \multirow{2}{*}{ Kriteriji kvalitete } & \multirow{2}{*}{$\begin{array}{l}\text { Ponder } \\
\text { kriterijuma (\%) }\end{array}$} & \multicolumn{3}{|c|}{ OCENA KVALITETA } \\
\hline & & Iznadprosečna & Prosečna & Ispodprosečna \\
\hline $\begin{array}{l}\text { SVOJSTVA PROIZVODA } \\
\text { 1. Imidž/Status } \\
\text { 2. Upotrebljivost } \\
\text { 3. Troškovi proizvoda } \\
\text { 4. Pouzdanost } \\
\text { 5. Ekološka štetnost } \\
\text { 6. ............ }\end{array}$ & \begin{tabular}{|l}
$(40)$ \\
5 \\
10 \\
10 \\
10 \\
5
\end{tabular} & 10 & $\begin{array}{l}10 \\
10\end{array}$ & 5 \\
\hline $\begin{array}{l}\text { KRITERIJUMI } \\
\text { USLUŽIVANJA KUPACA } \\
\text { 7. Savetovanje kupaca } \\
\text { 8. Ponavljanje porudžbine } \\
\text { 9. Vreme isporuke } \\
\text { 10. Garancije } \\
\text { 11. Postprodajni servis } \\
\text { 12. ..... }\end{array}$ & \begin{tabular}{|l}
$(60)$ \\
20 \\
10 \\
5 \\
10 \\
15
\end{tabular} & $\int_{15}^{10}$ & $\left.\right|^{20} 10$ & 5 \\
\hline UKUPAN KVALITET & 100 & 40 & 50 & 10 \\
\hline
\end{tabular}

Izvor: Izrada autora

Kvalitet proizvoda ocenjuje se po navedenim ili sličnim kriterijumima poređenjem s proizvodima tri najveća konkurenta. $U$ tabeli dobijene, rezultate primenjuje se sledeći postupak:

Relativni kvalitet:

- Bolje od proseka $+40 \%$

- Prosečna $50 \% \Delta$

- Slabije od proseka - $10 \%$

- Indeks kvaliteta $=+30 \%(+40-10)$.

Nakon utvrđivanja indeksa kvaliteta za svaki proizvod formiraju se kvalitativne grupe i izračunava ostvareni promet i procenat prometa po grupama kao podloga za utvrđivanje indeksa kvaliteta proizvodnog programa. Na taj način stvara se podloga za utvrđivanje snage ili slabosti koju pojedini proizvod ili proizvodni program strategijske poslovne jedinice unosi u konkurentnu snagu preduzeća. Zavisno od razlike indeksa moguće je stepenovanje i dalje diferenciranje snaga ili slabosti. Ocene zasnovane na mišljenju kupaca i ukupna ocena kvaliteta proizvoda nisu završni rezultat analize kvaliteta, to je samo pretpostavka za otkrivanje uzroka snaga i slabosti i precizranje analize polaznog strategijskog položaja. ${ }^{48}$ Koncentracija na snage i otklanjanje slabosti zahteva i mere koje osiguravaju dugotrajne izglede za nadprosečni uspeh.

Analiza prilika i pretnji koje se javljaju u okruženju druga su strana SWOT analize. Konjukturni ciklusi, životne faze branše ili neke druge promene u privrednom ili vanprivrednom okruženju predstavljaju promene stanja okruženja. Međutim, sve te promene su istovremeno moguće šanse i opasnosti za preduzeće. Budući se promene događaju kao opšti uslovi privređivanja, koji jednoliko deluju

${ }^{48}$ Gligorijević M. 2005. Marketing, Ekonomski fakultet, Beograd, str. 181. 
na sve konkurente i sve nosioce potreba, odgovor na pitanje je li neka promena šansa ili opasnost za preduzeće zavisi o tome kako se može odgovoriti na pitanje: Susreće li se neka promena s nekom našom snagom? Ako je odgovor DA, znači da nam okruženje nudi šansu i obrnuto ako je odgovor NE, znači da nas okruženje izlaže opasnostima.

Uparivanjem parametara potencijala izvan i u preduzeću moguće je usmeravati analizu šansi i opasnosti. Pragmatično, susretnu li se pogoršana pouzdanost novčanih tekova ili opšta nelikvidnost kao obeležje okruženja s nadprosečnom solventnosti i kreditnom sposobnosti kao snagom preduzeća navedena, u osnovi nepovoljna, promena okruženja postaće zanimljiva šansa preduzeća isto kao što povećanje rentabilnosti uz nesposobnost preduzeća da kontroliše troškove može se, radi ulaska novih konkurenata, umesto u šansu pretvoriti u opasnost.

Ekonomska strategija je utakmica između onoga šta preduzeće može da uradi (na bazi internih prednosti i slabosti) i onoga što bi trebalo da uradi (na bazi šansi i pretnji okruženja). Pretpostavka za formulisanje strategije je da postoji analitička objektivnost stratega u proceni relativnih mogućnosti preduzeća i šansi za razvoj tržišta. Stepen do kog stratezi žele da prihvate manji, ili veći rizik, zavisi od profitnih ciljeva. Ukoliko su profitni ciljevi veći, utoliko mora da se prihvati srazmerno veći rizik. Procena rizika treba da izrasta iz ograničenog broja opcija koje se zasnivaju na pažljivoj analizi preduzeća i okruženja sa kojim se suočava. Visok profitni cilj stratega može da bude u suprotnosti sa relativno nižim rizikom vlasnika. Kreiranje vrednosti će tada zavisiti od sposobnosti preduzeća da privuče nove investitore sa većom sklonošću ka riziku.

Preduzeće ima slobodu da bira načine kao i slobodu dodeljivanja prioriteta neekonomskim ciljevima. Kada se, međutim, dođe do područja ekonomskih prioriteta izbor je diktiran mnoštvom faktora koji su izvan kontrole menadžmenta. ${ }^{49}$ Centralno pitanje je da li preduzeće može da ostvaruje svoje ciljeve bez primene mera diversifikacije. Analitički okvir za rešavanje ovog strateškog pitanja se zasniva na internom i eksternom vrednovanju. Iz ugla vlasnika, kreiranje vrednosti suštinski zavisi od izbora ekspanzione ili diversifikacione strategije, ili njihove kombinacije. $U$ tom smislu, potrebno je napraviti razliku između zdravog i nezdravog rasta preduzeća. Zdrav rast je samo ukoliko stvara neto gotovinski tok. Rast imovine koji proizvodi negativan gotovinski tok znači uništavanje vrednosti. Mogućnost da rast imovine može da ima za posledicu negativan neto gotovinski tok govori o nepouzdanosti internih mera rentabilnosti ulaganja. Menadžment odluke ne mogu da budu agregirane u jednu matricu odlučivanja, sa faktorima koji se simultano razmatraju da bi se postiglo optimalno rešenje.

Struktura grane u kojoj se preduzeće nalazi određuje stanje konkurencije i okvir za reagovanje preduzeća. Okruženje je vrlo širok pojam koji obuhvata kako društvene, tako i ekonomske snage. Ključni aspekt okruženja preduzeća je grana, ili grane u kojima ono konkuriše. Precizno definisanje grane je veoma značajno pitanje, između ostalog i zato što postoji strah od previda potencijalnih izvora konkurencije. Pošto takva konkurencija može da postane ozbiljna pretnja grani jednog dana, nužno je da se upozori na slepilo uskog definisanja grane koje je zasnovano na proizvodu. ${ }^{50}$ Stanje konkurencije $u$ grani zavisi od pet konkurentskih snaga i to: 51

- $\quad$ pretnja konkurenata koji ulaze;

- pregovaračka snaga kupaca;

- pregovaračka snaga dobavljača;

- pretnja supstitutima i

- $\quad$ rivalitet između postojećih preduzeća.

Kada se kreiranje vrednosti stavi u kontekst grane, onda najvažnije razjasniti zbog čega su neke grane inherentno rentabilnije od drugih ${ }^{52}$ Odgovor se može potražiti u vezi sa atraktivnošću grane ${ }^{53}$. Sve grane nemaju isti potencijal rentabilnosti, jer konkurentske snage ispoljavaju različit uticaj u različitim granama. Cilj strategije preduzeća u okviru grane je da pronađe sebi mesto u grani gde može da se najbolje zaštiti od ovih sila, ili da na njih utiče u svoju korist čime povećava vrednost preduzeća. Poznavanje izvora konkurentskih pritisaka osvetljava kritične snage i slabosti preduzeća i animira ih na adekvatno pozicioniranje u grani. Postojanje pet konkurentskih snaga odražava činjenicu da konkurencija u grani nije predstavljena samo postojećim konkurentima. Ove naznake o suštini konkurencije u smislu "proširenog rivaliteta" imaju fundimentalan značaj za kreiranje vrednosti.

Atraktivnost grane predstavlja osnovu za formulisanje konkurentske strategije preduzeća. Na najopštijem nivou posmatranja mogu da se identifikuju tri interno konzistentne generičke strategije. To su: (1) vođstvo u troškovima; (2) difirenciranje i (3) fokusiranje. Navedene strategije mogu da se koriste pojedinačno, ili u kombinaciji. Na duži rok posmatrano, cilj preduzeća je da izgradi odbrambenu poziciju i nadmaši konkurente u grani.

\footnotetext{
${ }^{49}$ Ovi faktori se mogu posmatrati u vidu: kretanja cena na tržištu, deviznog kursa, inflacije itd.

50 Porter M., 1996. How Competitive Forces Shape Stragegy, The Dryden Press, p. 289

51 Pokrajčić D. 2004, Ekonomika preduzeća, Ekonomski fakultet, Beograd, str. 54

52 Bourgeouis L. J., 1996. Strategic Management from Concept to Implementation, The Dryden Press, p. 300

${ }^{53}$ Atraktivnost grane meri se prosečnom rentabilnošću, odnosno dugoročnim prinosom na investirani kapital. 
Ako preduzeće ne uspe u pokušaju da razvije bar jednu od nevedene tri strategije, onda ono upada u situaciju koja bi mogla da se nazove "zarobljen u sredini". Ova ekstremno loša situacija za preduzeće, po pravilu, povlači i nisku rentabilnost. ${ }^{54}$ Takva situacija je moguća u praksi pri različitim odnosima između rentabilnosti i tržišnog učešća. Preduzeća nezavisno od iznosa tržišnog učešća mogu da ostvaruju visoke stope prinosa.

Visoko tržišno učešće omogućava sve pogodnosti, što posledično vodi ka visokoj rentabilnosti. Nisko tržišno učešće može da omogući visoku rentabilnost kada se preduzeće orijentiše na uzak tržišni segment (fokusiranje), ili se njegov proizvod jasno diferencira u smislu unikata u odnosu na proizvode konkurencije. Najteža situacija je kada preduzeća nemaju prednost ni po jednom od pomenutih osnova. U takvim situacijama je moguće da se izabere jedinstvena diferencijacija zbog specijalnih karakteristika proizvoda, ili da se opredeli za redizajn sa ciljem da se proizvodi usmere ka pojedinačnom tržištu. U oba slučaja rezultat je malo tržišno učešće i visok rentabilitet. ${ }^{55}$

U nekim granama nema mogućnosti za fokus i diferencijaciju, pa se problem svodi na igru troškova. To je najčešće slučaj sa granama koje proizvode robu široke potrošnje. Razvoj grane značajno utiče na povećanje, ili smanjenje njene atraktivnosti. Dugoročni potencijal rentabilnosti zavisi od buduće strukture grane. Svaka grana ima svoju inicijalnu strukturu koja je predstavljena kombinacijom pet konkurentskih snaga.

Proces razvoja uslovljava granu ka njenoj potencijalnoj strukturi. Postoji mnogo faktora koji utiču na razvoj grane. Osnov dugoročnie rentabilnosti preduzeća nalazi se u konsolidaciji grana i perifernim okvirima grane. Konsolidacija grane najviše zavisi od međusobnog uticaja tri strukturna elementa i to: rivalnosti među konkurentima, barijera ulaska i barijera izlaska. Koncentracija grane i barijere ulaska su paralelni procesi. Ako postoje visoke barijere ulaska, ili posebno ako se one povećavaju, onda se gotovo uvek povećava koncentracija grane. ${ }^{56}$ Suprotno, ako su barijere ulaska niske, onda se ne ostvaruje koncentracija grane.

Izlazne barijere ograničavaju koncentraciju. One zadržavaju neuspešna preduzeća u grani, zbog čega lideri ne mogu da uživaju prednosti koncentracije. Evolucija grane ima snažnu tendenciju da pomera granice jedne grane, najčešće putem inovacija i supstituta. Posledica je da se povećava broj direktnih konkurenata u grani što zaoštrava pitanje rentabilnosti.

Pitanje atraktivnosti grane je naročito značajno za formiranje vrednosti usled prelaska sa nivoa strateških poslovnih jedinica i generičkih strategija na formulisanje strategije preduzeća. Porter navodi "test atraktivnosti" kao jedan od tri najvažnija kriterijuma za formulisanje strategije na nivou preduzeća.

Diversifikacija ne može da kreira vrednost sve dok nove grane ne poseduju povoljne strukture koje omogućavaju da prinosi premaše cenu kapitala. Ako grana nema takve prinose, onda preduzeće mora da bude u stanju da restrukturira granu, ili da ostvari trajnu konkurentsku prednost koja omogućava prinose iznad proseka grane. ${ }^{57}$ Problem je u tome što diversifikovana preduzeća nedovoljno prave razliku između indikatora kao što su atraktivnost grane i brzi rast.

Mnogi koji su požurili u brzo rastuće grane, računarska tehnika, robotika itd., pogrešili su, jer su zamenili teze o ranom rastu sa dugoročnim profitnim potencijalom. Grane su rentabilne ne zato što su one tehnološki savremene, već samo ako su njihove strukture atraktivne. ${ }^{58}$

Atraktivnost grane je korisna ne samo za analizu rentabilnosti, nego i za procenu rizika. Kada je rizik u pitanju potrebno je istaći podelu na sistematski i nesistematski rizik. Nesistematski rizik može se izbeći, ili smanjiti pomoću diversifikacije vlasničkih portfelja. Iz čega sledi da je rizik akcije sistematski rizik pa je nagrada za investitore u korelaciji sa njime. Ponekad naglasak samo na sistematsku komponentu rizika može da dovede do potcenjivanja stvarnog rizika akcionara. Što je veći stepen verovatnoće da će preduzeće biti nelikvidno, to je veći interes vlasnika za ukupan, a ne samo sistematski rizik. Menadžeri, takođe, pokazuju veći interes za ukupan rizik jer je njihov status vezan za preduzeće, za razliku od dobro diversifikovanih akcionara. U tom smislu je prihvatljivija podela rizika na poslovni i finansijski rizik.

Poslovni rizik je posledica neizvesnosti koja je karakteristična za poslovne aktivnosti preduzeća u grani i meri se fluktuacijom gotovinskog toka. Finansijski rizik je dodatni rizik koji nastaje uvođenjem finansijskih obaveza. Kombinacija poslovnog i finansijskog rizika određuje ukupan profil rizika preduzeća. Atraktivnost grane je korisna za analizu poslovnog rizika, jer svih pet konkurentskih snaga značajno utiču na poslovni rizik. Menadžment preduzima odbrambene mere radi sprečavanja poslovnog rizika u vidu visokih ulaznih barijera i/ili kontrareakcijom na pretnje od ulaska novih konkurenata u granu. Visoke ulazne barijere nameću dodatne fiksne troškove potencijalnim konkurentima. Posledično, brzi rast fiksnih u odnosu na ukupne troškove povećava poslovni rizik.

Ulazak novih konkurenata zahteva takve investicije kao što su diferencijacija proizvoda, pristup kanalima distribucije i slično. ${ }^{59} \mathrm{~S}$ obzirom da takve vrste investicija nemaju rezidualnu vrednost tim više je

\footnotetext{
${ }^{54}$ Porter M., 1980. Competitive Strategy: Techniques for Analyzing Industries and Competitors, The Free Press, p. 173

${ }^{55} \mathrm{Hax}$ A. and Majluf N., 1995. The use of Growth - Share Matrix in Strategic Planning, J. Willey \& Sons, p. 149

${ }^{56}$ Pokrajčić D., op. cit. 51

${ }^{57}$ Đorđević D. Mikroekonomija-savrmen pristup, Privredna akedemija, Novi Sad, str. 82

${ }^{58}$ Porter M., 1996. From Competitive Advantage to Corporate Strategy, Prentice Hall International, p. 301
} 
naglašen poslovni rizik. Kontrareakcija postojećih konkurenata se sprovodi putem cenovne konkurencije. $U$ tom smislu je značajan koncept cena koje ograničavaju ulaz. Ove cene uravnotežuju potencijalni dobitak od ulaska u novu granu sa očekivanim troškovima prevazilaženja ulaznih barijera.

Ako je tekući nivo cena u grani veći od nivoa cena koje ograničavaju ulaz, onda će potencijalni konkurenti moći da ostvare natprosečne profite po osnovu ulaza, i ulaz će se ostvariti. Postojeći konkurenti mogu se opredeliti za konkurenciju sa cenama koje su niže od nivoa cena koje ograničavaju ulaz. U tom slučaju odnos fiksnih troškova ulaska i nepovoljnih cena povećavaju poslovni rizik potencijalnih konkurenata. Kada su ulazne barijere niske i/ili kontrareakcija postojećih konkurenata slaba, postoji veća šansa da novi konkurenti uđu u granu. Posledice za postojeća preduzeća se ogledaju u fluktuaciji tražnje za njihovim proizvodima, što dovodi do povećanja poslovnog rizika. Intenzitet rivaliteta između postojećih konkurenata uzima uobičajenu formu pokušaja da se ostvari prednost nad konkurentima.

Repertoar mogućih taktika je veoma širok i može da bude u formi konkurencije cenama, reklamnih ratova i sl. Pojedine taktičke forme, a naročito konkurencija cenama, dovodi čitavu granu u lošiji položaj sa stanovišta rentabilnosti. Rivali veoma brzo i lako reaguju na snižavanje cena, što umanjuje prihode svih učesnika. Elastičnost cena je faktor rizika i ukoliko je intenzitet rivaliteta veći, utoliko se povećava i poslovni rizik. ${ }^{60}$ Postoje nekoliko strukturnih determinanti intenziteta rivaliteta, ali su izlazne barijere verovatno najvažnije. Često su izlazne barijere povezane sa ulaznim barijerama. Na primer, ekonomija obima (ulazne barijere) je povezana sa specijalizacijom (izlazna barijera). Sa stanovišta prinosa i rizika možemo zaključiti, najbolji slučaj je kada postoje visoke ulazne i niske izlazne barijere. Kada su istovremeno visoke i ulazne i izlazne barijere, ostvaruje se visok, ali rizičan prinos. Najgori slučaj je kada postoje niske ulazne, ali visoke izlazne barijere, jer su prinosi niski i praćeni su visokim poslovnim rizikom.

Opasnost od supstituta povećava poslovni rizik tako što utiče na varijabilnost tražnje u postojećoj grani. Pojava supstituta koja je često praćena nižim, atraktivnijim cenama, utiče da se tražnja za postojećim proizvodima u grani preusmerava upravo ka takvim proizvodima. Što je realnija opasnost od supstituta, to je veća promenljivost tražnje i poslovni rizik. Pregovaračka snaga kupaca utiče na senzitivnost cena. Akcije kupaca koje obaraju cene, zahtevaju bolji kvalitet i podstiču međusobnu konkurenciju proizvođača, izazivaju pogoršanje prinosa i veliku fluktuaciju cena. ${ }^{61}$ Pregovaračka snaga dobavljača ispoljava se kao otežano usklađivanje izlaznih u odnosu na ulazne cene preduzeća u grani. ${ }^{62}$ Zbog nemogućnosti da se prevale nepovoljni efekti ulaznih cena na krajnje kupce, povećava se poslovni rizik preduzeća, što utiče negativno na njegovu vrednost.

\section{TRŽIŠNO STVARANJE VREDNOSTI I KONKURENTSKE PREDNOSTI}

Konkurentska prednost se može posmatrati kao funkcija efikasnijeg obezbeđenja vrednosti u odnosu na konkurente (niski troškovi). S druge strane gledano, ona se može posmatrati kao izvršavanje aktivnosti po uporedivim troškovima, na način koji kreira više vrednosti za kupca u odnosu na konkurente što utiče na diferencijaciju. Klasična ekonomska teorija smatra da komparativnu prednost imaju ona preduzeća koja ostvaruju niže troškove na bazi jeftinih faktora proizvodnje i/ili položajne rente ${ }^{63}$ Resursi uključuju patente, prava robne marke, specijalizovana fizička sredstva i odnose preduzeća sa dobavljačima i kanalima distribucije. Isto tako značajan resurs je i reputacija koju preduzeće ima kod svojih zaposlenih, zatim dobavljača i kupaca.

Pozicija preduzeća se sastoji od proizvoda ili usluga koje obezbeđuje od tržišnih segmenata na kojima prodaje i od stepena zaštite od direktne konkurencije. Najbolje pozicije su one koje uključuju obezbeđenje jedinstveno vrednih proizvoda cenovno neosetljivim kupcima, nasuprot tome, loše pozicije su one koje znače nuđenje proizvoda marginalne vrednosti odlično informisanim i cenovno osetljivim kupcima. Postoje dve vrste pozicione konkurentske prednosti i to ${ }^{64}$ : prednost prvog pokretača $i$ pojačivači. Prva vrsta pozicione prednosti zahteva velike investicije u odnosu na tržište. Na primer, preduzeće koje prvo otvori veliki trgovinski diskont u ruralnom području, svojom relativnom veličinom ograničava pristup mogućih konkurenata. Druga vrsta pozicione prednosti pojačava ili štiti jak tržišni položaj preduzeća. Na primer, preduzeće može da iskoristi jaku marku postojećeg proizvoda kao pojačivač za uvođenje povezanih marki proizvoda.

Lanac vrednosti pokazuje ukupnu vrednost i sastoji se od aktivnosti koje utiču na vrednost, kao i marže profita. Marža profita predstavlja razliku između ukupne vrednosti i zbirnih troškova izvršenja

\footnotetext{
${ }^{59}$ Samuelson A. P., and Nordhaus D. W., 2000. Ekonomija, MATE, Zagreb, str. 218

60 Đorđević D. op. cit. 53

${ }^{61}$ Fluktuacija cena povećava poslovni rizik

${ }^{62}$ Gligorijević M. op. cit. 145

63 Gligorijević M. op. cit. 65

${ }^{64}$ Czinkota M, Ronkainen I. and Moffett M. 2003, International bussiness, Thomson learnig, South western, USA, p. 4-5
} 
aktivnosti. U kontekstu pokazatelja profitabilnosti (profitability ratios) uobičajeno se razmatraju pokazatelji marže profita (profit margin ili Umsatzrentabilitat), rentabilnost ukupne imovine (rate of return on total assets ili return on investment ili return on capital used) i rentabilnost vlastitog kapitala (return on equity). Postupak izračunavanja tih pokazatelja prikazan je u tabeli 2.

Tabela 2. Pokazatelji profitabilnosti ${ }^{65}$

\begin{tabular}{|c|c|c|}
\hline NAZIV POKAZATELJA & BROJILAC & IMENILAC \\
\hline Neto marža profita & neto dobit + kamate & ukupni prihod \\
\hline bruto marža profita & dobit pre poreza + kamate & ukupni prihod \\
\hline Neto rentabilnost imovine & neto dobit + kamate & ukupna imovina \\
\hline bruto rentabilnost imovine & dobit pre poreza + kamate & ukupna imovina \\
\hline $\begin{array}{l}\text { rentabilnost sopstvenog kapitala } \\
\text { (glavnice) }\end{array}$ & neto dobit & $\begin{array}{l}\text { sopstveni } \\
\text { (glavnica) }\end{array}$ \\
\hline
\end{tabular}

Marža profita izračunava se na osnovu podataka iz računa dobiti i gubitka (bilansa uspeha). Razlikuje se neto marža profita od bruto marže profita. Razlika je u obuhvatu poreza u brojiocu pokazatelja. Ako se uporede ta dva pokazatelja, tada poređenje govori o tome koliko relativno u odnosu na ostvareni ukupni prihod iznosi poresko opterećenje. Ako se marža profita pomnoži s koeficijentom obrta ukupne imovine, kao rezultat će se dobiti pokazatelj rentabilnosti imovine (neto ili bruto). To znači da se rentabilnost može povećati povećanjem koeficijenta obrta i/ili povećanjem marže profita.

Pokazatelji rentabilnosti računaju se na osnovu podataka iz bilansa stanja i računa dobiti i gubitka (bilansa uspeha). Pri utvrđivanju rentabilnosti imovine razlikuje se neto i bruto rentabilnost. I ovde je, kao kod marža profita, razlika u obuhvatu poreza u brojiocu pokazatelja. Prema tome, razlika između ta dva pokazatelja upućuje na relativno poresko opterećenje u odnosu na ukupnu imovinu. Osim tih pokazatelja, u kontekstu pokazatelja profitabilnosti obično se računa i rentabilnost sopstvenog kapitala, koja je zapravo i najznačajnija. Na osnovu poređenja rentabilnosti sopstvenog kapitala i rentabilnosti ukupne imovine kao i kamatne stope koja odražava cenu korišćenja tuđeg kapitala moguće je doći do zaključaka o stepenu korišćenja finansijske poluge (leverage-a), u okviru poslovnih aktivnosti preduzeća.

Aktivnosti se dele u dve šire grupe i to: (1) primarne aktivnosti i (2) aktivnosti podrške. Primarne aktivnosti, su fizičko stvaranje proizvoda, njegova prodaja i transfer kupcima, kao i postprodajne usluge preduzeća, dok aktivnosti podrške pružaju pomoć primarnim aktivnostima.

Aktivnosti u lancu vrednosti preduzeća nisu nezavisne među sobom. Način izvršavanja jedne aktivnosti često utiče na troškove ili efektivnost ostalih aktivnosti. Međuzavisnost aktivnosti postoji ne samo unutar preduzeća, nego i u odnosu na aktivnosti dobavljača, kanala distribucije i kupaca. Lanac vrednosti preduzeća predstavlja samo deo većeg toka aktivnosti koji se zove "sistem vrednosti"66. Konkurentska prednost preduzeća ne zavisi samo od njegovog lanca vrednosti, nego i od sistema vrednosti. Ravnoteža konkurentske moći u lancu vrednosti grane je vrlo važna. Na primer, preduzeće može da investira vrlo značajna sredstva u kvalitet svojih usluga, dodajući tako vrednost za kupce, ali može da pretrpi neuspeh zbog ograničene pregovaračke moći da realizuje dodatu vrednost putem povećanja cene. ${ }^{67}$

Preduzeće ostvaruje prednost u troškovima kada je ukupnost njegovih troškova manja od konkurentske. Troškovi indirektno utiču na diferenciranje koje predstavlja drugu vrstu konkurentske prednosti. Prednost u troškovima mora da bude postojana, što znači da se izvori konkurentske prednosti u troškovima teško imitiraju. Na konceptu lanca vrednosti se zasniva formulisanje nekoliko vrsta strategija preduzeća koje kreiraju njegovu vrednost. Ističu se dve takve strategije u kontekstu diversifikovanih preduzeća. ${ }^{68}$ Prva strategija koristi sličnosti u lancima vrednosti poslovnih jedinica za transfer veština ili stručnosti. ${ }^{69}$ Druga strategija se odnosi na deljenje aktivnosti u lancu aktivnosti između poslovnih jedinica. $\mathrm{Na}$ primer, različite poslovne jedinice dele zajednički sistem fizičke distribucije, prodajnu operativu i sl. Ponekad deljenje aktivnosti može da ima kontraefekat na konkurentsku prednost. To je naročito prisutno u uslovima visoke samostalnosti poslovnih jedinica, kada kompromisi narušavaju njihovu efektivnost.

\footnotetext{
${ }^{65}$ Izvor: Žager K. Žager L. Analiza financijskih isvještaja, Zagreb str. 204.

66 Šire videti: Schroeder R. and Clark M. 2001. Accounting Theory and Analysis, University of North Carolina, p. 89

${ }^{67}$ Grundy T., 1996. How Companies Can Avoid Destroying Shareholder Value, Kegan Paul, p. 90

${ }^{68}$ Porter M., op. cit., p. 320

${ }^{69}$ lako svaka poslovna jedinica ima svoj odvojen lanac vrednosti, znanje o tome kako se izvršavaju aktivnosti se transferiše između njih. Transfer veština uključuje one aktivnosti koje su značajne za komparativnu prednost poslovne jedinice primaoca. Grane koje su izabrane za diversifikaciju moraju da prođu test atraktivnosti.
} 
Ova dva pristupa omogućavaju menadžerima efekat leveridža na području veština i resursa, ukoliko se kombinuju na odgovarajući način. Menadžeri mogu da vrše leveridž resursa preduzeća na četiri načina ${ }^{70} \mathrm{i}$ to: 1) oni mogu da maksimiziraju prinose na interne resurse koncentrisanjem investicija i energije na ono što preduzeće najbolje može da radi, 2) dobro razvijena jezgra kompetencija obezbeđuju vrlo snažne barijere protiv sadašnjih i budućih konkurenata, 3) verovatno najveći leveridž je potpuno iskorišćenje investicija dobavljača, inovacija i specijalizovanih profesionalnih mogućnosti koje bi bile ograničavajuće skupe, ili neizvodljive u smislu internog finansiranja, 4) ova zajednička strategija smanjuje rizike, skraćuje vreme obrta, umanjuje investicije i kreira brže odgovore na potrebe kupaca u uslovima brzih tržišnih i tehnoloških promena.

Pragmatično "Nike" kompanija je izmestila skoro $100 \%$ svoje proizvodnje van matičnog jezgra, zadržavši proizvodnju samo nekoliko ključnih komponenti. "Nike" kompanija kreira maksimalnu vrednost koncentrišući se na predproizvodne (istraživanje i razvoj), kao i postproizvodne aktivnosti (distribucija i prodaja). Ove dve ključne aktivnosti su povezane u najbolji marketinški informacioni sistem u grani.

Operacionalizacija lanca vrednosti u preduzećima podrazumeva strateški pristup troškovima. Klasični računovodstveni sistem nije podesan za ove svrhe. Kategorizacija troškova jedne aktivnosti na direktne, indirektne i opšte troškove je ne samo uprošćena, već i artificijelna zbog agregiranja troškovnih pozicija koje imaju različito ponašanje.

Sve više gubi na značaju fizičko korišćenje faktora proizvodnje (kapitala i rada), kao tradicionalnih osnova za alokaciju troškova, dok se učešće usluga neprekidno povećava kod najvećeg broja preduzeća. Sistem obračuna troškova zasnovanih na aktivnosti polazi od pretpostavki da menadžeri treba da shvate kako se stvaraju troškovi u preduzeću radi identifikovanja ključnih faktora koji vuku troškove. Neophodno je ispitivanje da li procesi treba da se uproste ili izmene radi smanjenja troškova, ili dodavanja veće vrednosti. Nakon redizajna poslovnog procesa potrebno je da se prate ostvarenja većeg broja pokazatelja na području ključnih pokretača vrednosti i pokretača troškova. ${ }^{71}$

U skladu sa ovim pretpostavkama može da se pristupi strategijskoj analizi troškova u funkciji kreiranja vrednosti preduzeća. Za tu svrhu neophodno je definisanje lanca vrednosti i alociranje troškova na različite oblike imovine u vidu fiksnih i obrtnih sredstava u skladu sa odgovarajućim aktivnostima. Povezivanje aktive sa aktivnostima se opravdava činjenicom da količina i efikasnost korišćenja aktive značajno utiču na troškove. Predmet strategijske analize troškova jesu one aktivnosti koje imaju signifikantno i/ili rastuće učešće u ukupnim troškovima ili angažovanoj aktivi. Isto tako u analizu se uključuju aktivnosti čiji različiti faktori vuku troškove. Troškovi se alociraju na aktivnosti koje in prouzrokuju. Postoje dva načina za alociranje aktive na aktivnosti. Jedan način je na osnovu knjigovodstvene vrednosti, a drugi prema vrednosti zamene. ${ }^{72}$ Aktiva se alocira na aktivnosti koje je koriste, kontrolišu, ili najviše utiču na njenu upotrebu.

\section{KONKURENTSKI POLOŽAJ PREDUZEĆA U OKVIRU GRANE}

Preduzeće može da se nađe u vrlo atraktivnoj grani, ali slab konkurentski položaj može značajno da ograniči kreiranje njegove vrednosti. $U$ skladu sa tim može se u okviru iste grane razlikovati rentabilnost poslovanja preduzeća. Preduzeća ne mogu da utiču na atraktivnost grane, ali mogu da formulišu različite konkurentske strategije radi povećanja svoje rentabilnosti u grani. Preduzeća mogu da izmene svoj relativan položaj u grani izabranom strategijom, čineći je manje ili više atraktivnom za kreiranje vrednosti. Preduzeće sa niskim cenama obično ima poziciju niskih troškova i dobar, iako ne superioran, kvalitet proizvoda. Strateška grupa je grupa preduzeća u nekoj grani koja prati istu ili sličnu strategiju duž strateških dimenzija. ${ }^{73}$ Strateške grupe ${ }^{74}$ su posrednici između grane kao celine i pojedinačnog preduzeća, one imaju različit rentabilitet zbog nejednakog uticaja pet konkurentskih snaga. Barijere mobilnosti ${ }^{75}$ su prvi ključni razlog zbog kog su neka preduzeća u grani rentabilnija nego druga. Preduzeće u strateškim grupama koje se odlikuju većim barijerama mobilnosti imaju veću rentabilnost u odnosu na preduzeća iz grupe sa niskim barijerama mobilnosti. Strateške grupe se međusobno razlikuju i prema pregovaračkoj snazi koju ispoljavaju u kontaktu sa kupcima i dobavljačima. Strategije ovih grupa su različito osetljive na zajedničke kupce ili dobavljače. Ponekad ove strategije imaju posla sa različitim kupcima i dobavljačima, što podrazumeva i različite nivoe pregovaračke snage. Stepen do kojeg pregovaračka snaga grupe može da varira zavisi od grane. Strateške grupe u pojedinim granama mogu

\footnotetext{
${ }^{70}$ Quinn J. B. and Himler F. G., 1996. Core Competincies and Strategic Outsourcing, Prentice Hall International, p. 311

${ }^{71}$ Grundy T., 1996. op. cit. 321

72 Stevanović N, Malinić D, Milićević V, Upravljačko računovodstvo, Ekonomski fakultet, Beograd, str. 209

${ }^{73}$ Krown J. 2003. Public Auditing, Barush College, p. 175

${ }^{74}$ Strateške grupe nisu ekvivalent tržišnim segmentima, jer se oni definišu na osnovu šire koncepcije strateškog položaja. Tržišni segment je uži pojam koji obuhvata identifikovanje razlika u potrošačkim potrebama i načinima kupovine, kako bi se formulisale adekvatne marketing strategije.

${ }^{75}$ Ulazne barijere mogu da se opštije predstave kao barijere mobilnosti.
} 
suštinski biti u istom položaju u odnosu na kupce i dobavljače. One mogu da se suočavaju i sa različitim nivoima konkurencije po osnovu proizvoda supstituta. Takve razlike imaju za posledicu veću ili manju osetljivost na supstitute, iako strateške grupe pripadaju istoj grani.

Barijere mobilnosti, pregovaračka snaga, osetljivost na supstitute i izloženost rivalitetu (konkurenciji) su osnovne karakteristike strateških grupa. S druge strane, vrednost preduzeća u strateškoj grupi zavisi od nekoliko činilaca. To su: stepen konkurencije unutar grupe, veličina preduzeća u odnosu na ostala preduzeća u grupi, troškovi ulaska u grupu i sposobnost preduzeća da realizuje izabranu strategiju u operativnom smislu. Preduzeće će biti najrentabilnije i imaće najveću vrednost ako se nalazi u atraktivnoj grani, povoljnoj strateškoj grupi u okviru grane i ako ima jaku poziciju u grupi. Formulisanje konkurentske strategije u nekoj grani može da se posmatra kao izbor strateške grupe u kojoj preduzeće želi da se takmiči.

Najopštiji vodič za formulisanje strategije je suprotstavljanje snaga i slabosti prema šansama i opasnostima iz okruženja. Tri generičke strategije: vođstvo u troškovima, diferenciranje i fokusiranje, mogu da budu veoma korisne za pozicioniranje preduzeća u grani. Naime, preduzeće može da koristi generičke strategije za kreiranje barijera mobilnosti, za stvaranje povoljnijeg položaja u odnosu na ostale kupce, dobavljače i supstitute, kao i za zaštitu od konkurencije, što direktno utiče na njegovu vrednost. Generičke strategije doživljavaju mnogo jasniju i operativniju razradu u okviru koncepta strateških grupa. Posledično, kreiranje vrednosti dobija svoj puni smisao u takvim uslovima. Realizovanje bar jedne od tri navedene generičke strategije u okvirima strateške grupe omogućava popravljanje relativnog položaja preduzeća u grani i povećava vrednost i obratno.

\section{CENOVNO USKLAĐIVANJE I MODELI UTICANJA NA NECENOVNE FAKTORE}

Cene mogu da imaju veoma značajnu ulogu u u funkciji kreiranja vrednosti preduzeća. U socijalističkim ekonomijama, efekti cena na usklađivanje preduzeća su slabi i imaju sekundarni značaj u odnosu na necenovne mehanizme. Preduzeća reaguju na promene cena, ali isto tako i utiču na njih.

Preduzeće reaguje na promene cena tako što usklađuje količinu i strukturu svojih inputa i outputa. U mikroekonomskoj teoriji, usklađivanje količine i strukture na strani inputa, ili tražnje, naziva se dohodni i supstitucioni efekat promene cena, respektivno. U nastavku rada se istražuju oba pomenuta efekta, kao i odgovarajuća usklađivanja na strani outputa ${ }^{76}$ Kada cene inputa rastu, tražnja za njima se smanjuje zato što isti budžet ${ }^{77}$ sada može da realizuje manju količinu nabavki. Ovo je suština dohodnog efekta koji važi u uslovima čvrstog budžetskog ograničenja. Kada postoji meko budžetsko ograničenje, dohodni efekat se ne materijalizuje. Ako preduzeće ima tražnju za nekim inputom, onda će ono da ostvari kupovinu bez obzira na veću cenu. U slučaju da povećani troškovi ne mogu da se pokriju u granicama budžetskog ograničenja, preduzeće će ovaj porast troškova, pre ili kasnije, da prevali na kupce ili državu.

Tražnja preduzeća za inputima je neelastična u netržišnim ekonomijama. Efekat supstitucije se ispoljava kao uticaj relativnih cena na izbor između alternativnih inputa. Za razumevanje efekta supstitucije neophodno je da se ukaže na proces formiranje inicijalne tražnje. Inicijalna tražnja je ponderisani prosek (1) tražnje koja reaguje na promenu cena i (2) tražnje koja na takve promene ne reaguje. ${ }^{78}$ Ponder se označava kao tzv. damper efekat čija ekonomska interpretacija je sledeća: upravo je relativna težina necenovnih signala ta koja smanjuje uticaj cena. Necenovni signali najčešće su u obliku instrukcija nadređenih autoriteta u vezi sa alokacijom materijala, inputnih kvota i sl. Ukoliko je stepen budžetskog ograničenja veći, utoliko necenovni efekti imaju manji značaj u formiranju inicijalne tražnje i obrnuto; niži stepen budžetskog ograničenja povećava relativan značaj necenovnih efekata.

Težnja ka kvantitativnoj ekspanziji pomera tradicionalno preduzeće planske privrede ka punom iskorišćenju kapaciteta. Puni kapacitet ne znači maksimum proizvodnje koja može da ostvari u idealnim uslovima, već maksimum u okviru datih resursnih ograničenja. Pri tome je moguće da cene ne pokrivaju marginalne troškove u zoni blizu punog korišćenja kapaciteta. Ipak, to ne sprečava preduzeće da povećava proizvodnju. Ako preduzeće ostvari gubitke zbog povećanja outputa, onda će verovatno država, ili kreditni sistem, da pokriju gubitke kroz cenovnu podršku, subvencije, ili kredite sa posebnom namenom. Mnogo češće cena je ta koja se usklađuje prema povećanim troškovima usled većeg obima proizvodnje. Struktura proizvodnje je u velikoj meri determinisana naporima preduzeća da ostvare plan.

Poslovanje preduzeća predstavlja jedan dinamičan proces u kome dolazi do stalnih promena. Ovakve promene nastaju uporedo sa promenama ili razvojem drugih preduzeća. Sa stanovišta upravljanja razvojem, odnosno sa stanovišta stvaranja vrednosti, treba saznati kakve su promene nastale ili bi trebale da nastanu. Pri tome nije važno samo to, da se saznaju promene koje su nastale u preduzeću u odnosu na prethodni period, odnosno u odnosu na prethodnu etapu razvoja, već je značajno

\footnotetext{
${ }^{76}$ Kornai J., 1980. Economics of Shortage, vol A - B, North - Holland, p. 290

77 Siglitz, J. 2004. Ekonomija javnog sektora, Ekonomksi fakultet, Beograd, str. 239

${ }^{78}$ Đorđević D. op. cit. 200
} 
saznati kako su se te promene odrazile na odnos sa drugim preduzećima. Dakle, upravljanje razvojem zahteva, da se saznaju promene u odnosu na prethodni period i da se saznaju promene položaja preduzeća u okruženju, odnosno promene u odnosu na druga preduzeća.

Ukoliko inputni miks postaje skuplji, utoliko preduzeća više smanjuju nivo svog outputa. ${ }^{79}$ Indeks troškova zavisi od dva faktora: učešća troškova inputa u vrednosti outputa preduzeća, kao i od kretanja cena inputa koji se konkretno koriste u proizvodnji. To znači da su radno-intenzivna preduzeća inicijalno u boljoj situaciji za suočavanje sa šokovima na strani ponude.

Vrednost preduzeća se bazira na necenovnim i cenovnim usklađivanjima preduzeća u njihovim različitim ulogama kao proizvođača, kupca inputa, prodavca i investitora. Pod uticajem liberalizacije trgovine i odsustva ulaznih barijera, resursno ograničenje se transformiše u ograničenje tražnje. Promena tražnje ima svoju agregatnu i specifičnu gransku dimenziju. Intenziviranje konkurencije i promene ukusa i preferencija kupaca preusmeravaju tražnju od inferiornih ka superiornim strateškim grupama u grani.

Iz mikroekonomskog ugla, usklađivanje ponude prema tražnji se ispoljava kao generalna tendencija opadanja industrijske proizvodnje. Preduzeća u ulozi proizvođača vrše trenutna i kratkoročna usklađivanja. Dugoročno usklađivanje je povezano sa njihovom ulogom kao investitora. Suština trenutnog usklađivanja je u prilagođavanju outputa uskim grlima u proizvodnji i forsiranoj supstituciji inputa i asortimana gotovih proizvoda. ${ }^{80}$

\section{ZAKLJUČAK}

Potrošačka tražnja stanovništva zavisi od raspoloživih dohodaka pojedinaca. Raspoloživi dohoci se sastoje od dohodaka koje stanovništvo prima od preduzeća, plus transferna primanja od države (penzije, osiguranje protiv nezaposlenosti i sl.), minus direktni porezi koji se plaćaju državi. Raspoloživi dohoci stanovništva su namenjeni potrošnji i štednji. S druge strane investiciona tražnja se sastoji od željenih ili planiranih nabavki kapitalnih sredstava i zaliha od strane preduzeća, i ona uglavnom zavisi od prognoza buduće tražnje za outputom, kao i od investicione kamatne stope.

S obzirom da ne postoji siguran način za procenu buduće tražnje, investicije mogu značajno da fluktuiraju, a time i potencijalna vrednost preduzeća. Javna tražnja za proizvodima i uslugama direktno doprinosi agregatnoj tražnji. Najvažniji segmenti javne tražnje za proizvodima i uslugama jesu zdravstvo i odbrana. Socijalna davanja, kamate na javni dug, kao i subvencije privatnim i državnim preduzećima, predstavljaju transferna plaćanja. Transferna plaćanja ne doprinose povećanju nacionalnog dohotka i outputa, već služe kao instrumenti za njihovu redistribuciju. Javna i investiciona tražnja predstavljaju autonomne komponente agregatne tražnje. One se direktno ne menjaju sa promenom tekućeg dohotka i outputa.

U liberalnoj ekonomiji, izvoz predstavlja značajan izvor tražnje za domaćim proizvodima. Izvozna tražnja najvećim delom zavisi od događanja u inostranim ekonomijama. Zbog toga se tražnja za izvozom tretira kao autonomna, tj. nije povezana sa nivoom domaćeg dohotka. Uvoz iz ostatka sveta može biti u obliku sirovina za potrebe domaće proizvodnje, ili proizvoda koji su namenjeni finalnoj potrošnji. Tražnja za uvozom se povećava sa rastom domaćeg dohotka i outputa. Uobičajeno gledište je da uvoz "krade" poslove domaće ekonomije. Zbog toga smanjivanje uvoza može da kreira dodatnu proizvodnju i zaposlenost kod kuće. Analiza komponenti agregatne tražnje omogućava procenu ukupnog volumena tražnje jedne grane. Za vrednost preduzeća najznačajnije je kako taj volumen alocirati unutar grane.

\section{LITERATURA}

1. Gligorijević M. 2005. Marketing, Ekonomski fakultet, Beograd

2. Porter M., 1996. How Competitive Forces Shape Stragegy, The Dryden Press

3. Pokrajčić D. 2004, Ekonomika preduzeća, Ekonomski fakultet, Beograd

4. Bourgeouis L. J., 1996. Strategic Management from Concept to Implementation, The Dryden Press

5. Porter M., 1980. Competitive Strategy: Techniques for Analyzing Industries and Competitors, The Free Press

6. Hax A. and Majluf N., 1995. The use of Growth - Share Matrix in Strategic Planning, J. Willey \& Sons,

7. Đorđević D. Mikroekonomija-savrmen pristup, Privredna akedemija, Novi Sad

8. Porter M., 1996. From Competitive Advantage to Corporate Strategy, Prentice Hall International

9. Samuelson A. P., and Nordhaus D. W., 2000. Ekonomija, MATE, Zagreb

10.Czinkota M, Ronkainen I. and Moffett M. 2003, International bussiness, Thomson learnig, South western, USA

11.Schroeder R. and Clark M. 2001. Accounting Theory and Analysis, University of North Carolina

12. Grundy T., 1996. How Companies Can Avoid Destroying Shareholder Value, Kegan Paul

\footnotetext{
${ }^{79}$ Hinds M., 1992. Policy Effectiveness in Reforming Socialist Economies, The World Bank, p. 178

${ }^{80}$ Begg D., Fischer S. and Dornbusch R., 1997. Economics, The MC Graw Hill, p.298
} 
13. Quinn J. B. and Himler F. G., 1996. Core Competincies and Strategic Outsourcing, Prentice Hall International

14.Stevanović N, Malinić D, Milićević V, Upravljačko računovodstvo, Ekonomski fakultet, Beograd

15. Krown J. 2003. Public Auditing, Barush College

16. Kornai J., 1980. Economics of Shortage, vol A - B, North - Holland

17.Siglitz, J. 2004. Ekonomija javnog sektora, Ekonomksi fakultet, Beograd

18. Hinds M., 1992. Policy Effectiveness in Reforming Socialist Economies, The World Bank

19.Begg D., Fischer S. and Dornbusch R., 1997. Economics, The MC Graw Hill

\section{ABSTRACT}

Competition as a general precondition for the company evolved into the modern system of business caused by the diversification of the relevant factors. The competitive process consisting of three interconnected and conditioned elements. In the first, the analysis of competitive forces shows why some of the branches are inherently cost-effectively, or more attractive than others and why in these branches grow enterprise value.

In the second the characteristics of strategic groups ii position within it can significantly impact the relative position of companies in the industry and time course of its value. In the third and last step, value chain analysis is used to identify the sources of competitive advantage. Creation of enterprise value Abstracting these factors by using different methods and procedures in determining market position.

Key words: competition, enterprise, value, market position. 